\title{
CHILDHOOD IMMUNIZATION AMONG INTERNALLY DISPLACED PERSONS (IDPS) OF UNDER FIVE-YEARS FROM NORTH WAZIRISTAN AGENCY, PAKISTAN: A CROSS SECTIONAL STUDY.
}

\author{
Shezina Sultan Ali ${ }^{1 *}$, Ejaz Ahmad Khan², Mudassar Mushtaq ${ }^{3}$, Mujib Ur Rahman $^{4}$
}

${ }^{1} \mathrm{MSPH}$ Health Services Academy \& Intern Department of Epidemiology, biostatistics and environmental health, Health Services Academy, ${ }^{2}$ Associate Professor and Head. Department of Epidemiology, biostatistics and environmental health, Health Services Academy, ${ }^{3}$ Assistant Professor, Department of Epidemiology, Biostatistics and Environmental Health, Health Services Academy, ${ }^{4}$ Divisional M\&E officer, Health Department , Khyber Pakhtunkhwa. *Corresponding author: Shezina SultanAli. Email: shezinapatel@gmail.com

\begin{abstract}
Background: Immunization is an important and cost effective public health tool for controlling Vaccine Preventable Diseases (VPDs) among children. Developing countries have low level of immunization coverages. This is further compromised during armed conflicts and disasters with displacement of vulnerable populations leading to VPDs outbreaks. Tribal areas of Pakistan have been subjected to armed conflict for a long time with massive population displacement.

Methods: We conducted a cross sectional survey to assess the vaccination status of child under five of the Internally Displaced Persons (IDPs) of North Waziristan Agency (NWA) of Pakistan. We used a structured questionnaire to collect information from the caregivers in the IDP camp of Bannu, Khyber Pakhtukhwa.

Results: Overall immunization coverage was very low. Out of 480 children under 5 years, less than one-third $(30.6 \%)$ were vaccinated against BCG, about a quarter $(27.7 \%)$ had received the Pentavalent and measles vaccines. However, OPV coverage was excellent mostly amid to polio mass campaigns.

Conclusion: Routine immunization coverage among the IDPs of North Waziristan agency in Pakistan is extremely poor. There is a need to improve the coverage to optimum level to avert any potential VPD outbreaks.
\end{abstract}

Key words: Vaccination, fully immunized child, disasters, developing countries

\section{Introduction}

Childhood Immunization is a preventive health behavior that is directed toward the child by parent. Vaccination can provide reduction in human grief and increase in life expectancy. Immunization is the most effective health investment as it is considered as major backer in Public health world Health Organization (WHO) defines Immunization as the process whereby a person is made immune or resistant to an infectious disease, typically by the administration of a vaccine. Vaccines stimulate the body's own immune system to protect the person against subsequent infection or disease. This has further been explored, in the past, in understanding preventive measures against diseases through robust vaccination programs. Immunization describes the whole process of delivery of a vaccine and the immunity it generates in an individual and population. Immunization is an important and cost effective public health tool for disease control. It reduces both morbidity and mortality among children due to vaccine preventable diseases Pakistan initiated its Expanding Programme on Immunization (EPI) during 1978 with support of World Health Organization (WHO) and the United Nations Children's Fund (UNICEF). Since then, it is vaccinating children under 2 years of age against six and now nine EPI diseases. It also provides mass campaigns against Polio, Measles and Tetanus (pregnant mothers) to cover the immunity gap left over by sub-optimally performing Routine Immunization (RI). The nine disease being catered for are: BCG, OPV, diphtheria, tetanus, pertussis, and measles, hepatitis $B$ and Haemophilus influenza type b (Hib), and it plans to introduce some more new an underused vaccines in the $\mathrm{RI}$.

A child requires at least nine months to receive immunizations for the six vaccine-preventable diseases (namely, tuberculosis, diphtheria, whooping cough, tetanus, polio, and measles). BCG (for tuberculosis) should be given at birth or at first clinical contact, DPT (for diphtheria, whooping cough and tetanus) and Polio require three dosages at approximately four, eight and twelve weeks of age, and measles should be given at or soon after reaching nine months of age.- The Demographic and Health Surveys (DHS) which are conducted in many countries collect information on the immunizations received by all the children (of the households covered in the surveys) born in the five years preceding the surveys. In the case where a child has received DPT3 and Measles 1 vaccine along with the OPV3, the child is considered to be a Fully Immunized Child (FIC) - . However, considering the presumption that immunization coverage could be very 
low, we took under-five population for a better sampling frame.

\section{Methodology}

We conducted this cross sectional survey in the IDP camps of district Bannu Khyber Pakhtunkhwa, Pakistan. The Internal Review Board (IRB) of the Health Services Academy, Islamabad, granted ethical approval. Sample size was calculated based on the $54 \%$ immunization coverage of Pakistan at an absolute precision equal to 0.05 and an estimated population size of 50,000. We calculated a sample size of 436 , which was increases by $10 \%$ to cover any refusals to bring it at 480 . Thus, we identified 480 children under five years, and informed consent was obtained from their caregivers who responded to a structured questionnaire on immunization status. Mainly, the vaccination status was recorded for card retention and recall. BCG mark was also identified to document $B C G$ vaccination at birth.

\section{Results}

Socio demographic Characteristics:

Table 1 shows that most of the respondents were females, were housewives, being of mean age of 38 years and majority of them were illiterate.

Table 1. Socio demographic Characteristics of the Participants

\section{Socio-demographic Characteristics of study respondents $(n=480)$}

\begin{tabular}{|l|l|l|}
\hline Characteristics & Frequency & Percentage \\
\hline Age & & \\
\hline Above 65 years & 406 & 84.6 \\
\hline Sex & 74 & 15.4 \\
\hline Male & & \\
\hline Female & 16 & 3.3 \\
\hline Education & 464 & 96.7 \\
\hline Illiterate & & \\
\hline Primary & 444 & 92.5 \\
\hline Middle & 32 & 6.7 \\
\hline Profession & 4 & 0.8 \\
\hline Housewives & & \\
\hline Government & 469 & 97.7 \\
\hline Private & 9 & 1.9 \\
\hline
\end{tabular}

The results shown below had source of data from card $(2.4 \%)$ and rest by recall depicting very poor vaccination card retention. Table 2 details the percentage of children immunized against VPDs, which was quite low. Less than one third of the sampled children were found to be vaccinated against BCG. Out of those vaccinated most could be identified from scar. Most of the children received OPV at the time of birth. As it is clear from the above table that only one-fourth of the under-five children $(27.7 \%)$ were immunized against pentavalent and measles.

Table 2: Status of immunization under 5 years of age

\begin{tabular}{|l|l|l|}
\hline $\begin{array}{l}\text { Status of immunization of children under } 5 \text { years } \\
\text { (n=480) }\end{array}$ & Frequency & Percentage \\
\hline Antigens & 147 & 30.6 \\
\hline BCG & 314 & 65.4 \\
\hline OPV at the time of birth & 332 & 69.2 \\
\hline OPV 1 & 341 & 71.0 \\
\hline OPV 2 & 348 & 72.5 \\
\hline OPV 3 & 133 & 27.7 \\
\hline Pentavalent 1 & 125 & 26.0 \\
\hline Pentavalent 2 & 125 & 26.0 \\
\hline Pentavalent 3 & 133 & 27.7 \\
\hline Measles 1 & 126 & 26.3 \\
\hline Measles 2 & & \\
\hline
\end{tabular}

\section{Discussion}

The country's overall coverage is less than $80 \%$. The administrative coverage data from the NWA has been reported around $47 \%$ to $52 \%$. Our study finds that the status of immunization in children under five years is very low in the NW agency (Table 2). These results are in compliment with a past local hospital based study. Other displaced populations from conflict zones suffer from the similar lower rates as compared to national figures .

Bacillus Calmette-Guérin (BCG) is given at birth. For the country, it remains around and well-above $80 \%$ regardless of failure to immunize against other VPDs. We found this around $31 \%$, which is much lower than rest of the country. Immigrants and displaced populations in other countries suffered the similar lower levels of BCG vaccination status .

Pakistan is one of those last countries, which are struggling to get rid of polio. Regardless of the campaigns conducted by a separate polio eradication initiative, the routine coverage of polio at birth and subsequent booster administration remains below optimum. This is also evident from our study results. The polio vaccination coverage is severely compromised during conflicts and resulting mass displacements. Even the most robust systems of immunization do break down. The example of Syrian crisis is the one. 
Vaccination coverage in Syria is estimated to have dropped from $91 \%$ in 2010 to as low as $45 \%$ in some regions by 2013 , indicating rapid collapse of immunization systems in conditions of war. Out of the 1.8 million Syrian children born since the conflict, over $50 \%$ are unvaccinated. Consequently, 36 cases of poliomyelitis were officially reported after 15 years of polio eradication. Nonetheless, already struggling health systems suffer much more as we present in our study results .

The coverage against Pentavalent vaccine was also poor $(26 \%)$. Other studies from African countries experiencing conflict has similar coverage results. Pentavalent covers against five VPDs i.e Diphtheria, Pertussis, Tetanus, Hep B and Hib. Pakistan has it in its EPI programme since 2008. There has never been enough coverage to cross overall $90 \%$ mark to achieve full immunization of pentavalent rendering children vulnerable to outbreaks of diphtheria or meningitis.

We found measles coverage very poor. Both the first and the second doses just covered around a quarter of the target population. Such conditions amid any outbreak of the disease when measles remain a highly contagious disease. These conditions usually worsen during complex humanitarian situations. In 2004, concurrent measles outbreaks occurred in four camps hosting 2767 Liberian refugees in Côte d'Ivoi. From 19 January to 23 February 2004 (weeks 8-13), measles IgM testing depicted $61.1 \%$ being positive. The highest incidence rate $(18.5 \%)$ of measles was observed in children aged $<9$ months. Lower vaccination coverage among displaced populations increase the risk of measles outbreaks, and the mortality in such conditions is usually quite high .

\section{Conclusion}

Overall vaccination coverage among the Internally Displaced Persons (children under five) is very low. Risk of disease outbreak remains very high until mass vaccination is conducted among the IDPs' camps, and efforts are made to improve coverage in the conflict zones and host populations.

\section{References:}

1. Bhutta, Z.A., et al., Reproductive, maternal, newborn, and child health in Pakistan: challenges and opportunities. The Lancet, 2013. 381(9884): p. 2207-2218.

2. Bondy, J.N., et al., Identifying the determinants of childhood immunization in the Philippines. Vaccine, 2009. 27(1): p. 169-175.

3. Anderson, R.M. and R.M. May, Immunisation and herd immunity. The Lancet, 1990. 335(8690): p. 641-645.

4. Shukla, B. and U. Kaur, Study to assess the effectiveness of structured teaching programme on knowledge among the adolescent boys regarding ill effects of smoking in selected Government Schools of Moga, Punjab. IARS'International Research Journal, 2014.4(01).
5. Hasan, Q., A. Bosan, and K. Bile, A review of EPI progress in Pakistan towards achieving coverage targets: present situation and the way forward. 2010.

6. Salama, P., P. Spiegel, and R. Brennan, No less vulnerable: the internally displaced in humanitarian emergencies. The Lancet, 2001. 357(9266): p. 1430.

7. Bos, E. and A. Batson, Using immunization coverage rates for monitoring health sector performance. Health, Nutrition and Population (HNP) Discussion Paper, World Bank, 2000.

8. de Timóteo Mavimbe, J.C., et al., Immunization coverage in Mozambique: from concepts to decision-making. Health policy, 2006. 79(1): p. 92100.

9. Phuong, C., The international protection of internally displaced persons. Vol. 38. 2005: Cambridge University Press.

10. Huhn, G.D., et al., Vaccination coverage survey versus administrative data in the assessment of mass yellow fever immunization in internally displaced persons-Liberia, 2004. Vaccine, 2006. 24(6): p. 730-737.

11. Connolly, M.A., et al., Communicable diseases in complex emergencies: impact and challenges. The Lancet, 2004. 364(9449): p. 1974-1983.

12. Moss, W.J., et al., Child health in complex emergencies. Bulletin of the World Health Organization, 2006. 84(1): p. 58-64.

13. Nishikiori, N., et al., Who died as a result of the tsunami?-Risk factors of mortality among internally displaced persons in Sri Lanka: a retrospective cohort analysis. BMC public health, 2006. 6(1): p. 73.

14. Feikin, D.R., et al., Mortality and health among internally displaced persons in western Kenya following post-election violence, 2008: novel use of demographic surveillance. Bulletin of the World Health Organization, 2010. 88(8): p. 601-608.

15. Akresh, R., L. Lucchetti, and H. Thirumurthy, Wars and child health: Evidence from the Eritrean-Ethiopian conflict. Journal of development economics, 2012. 99(2): p. 330-340.

16. Brown, D.W. and M. Gacic-Dobo, Home-based record prevalence among children aged 12-23 months from 180 demographic and health surveys. Vaccine, 2015. 33(22): p. 2584-93.

17. Shahab, F., H. Hussain, and H. Gul, Vaccination status and causes of under vaccination in paediatric patients admitted at Khyber teaching hospital Peshawar. Journal of Postgraduate Medical Institute (Peshawar-Pakistan), 2013. 27(4).

18. Melhem, N., K. Kreidieh, and S. Ramia, The Syrian refugees crisis brings challenges to the health authorities in Europe: hepatitis A virus is a case in point. European journal of epidemiology, 2016. 
31(7): p. 711-714.

19. Ozaras, R., et al., The Syrian conflict and infectious diseases. Expert review of anti-infective therapy, 2016. 14(6): p. 547-555.

20. Eskiocak, M., B. Marangoz, and N. Etiler, HEALTH PROBLEMS OF REFUGEES. WAR, MIGRATION AND HEALTH; EXPERIENCE OF TURKEY: p. 34.

1. Bhutta, Z.A., et al., Reproductive, maternal, newborn, and child health in Pakistan: challenges and opportunities. The Lancet, 2013. 381(9884): p. 2207-2218.

2. Bondy, J.N., et al., Identifying the determinants of childhood immunization in the Philippines. Vaccine, 2009. 27(1): p. 169-175.

3. Anderson, R.M. and R.M. May, Immunisation and herd immunity. The Lancet, 1990. 335(8690): p. 641-645.

4. Shukla, B. and U. Kaur, Study to assess the effectiveness of structured teaching programme on knowledge among the adolescent boys regarding ill effects of smoking in selected Government Schools of Moga, Punjab. IARS'International Research Journal, 2014. 4(01).

5. Hasan, Q., A. Bosan, and K. Bile, A review of EPI progress in Pakistan towards achieving coverage targets: present situation and the way forward. 2010.

6. Salama, P., P. Spiegel, and R. Brennan, No less vulnerable: the internally displaced in humanitarian emergencies. The Lancet, 2001. 357(9266): p. 1430.

7. Bos, E. and A. Batson, Using immunization coverage rates for monitoring health sector performance. Health, Nutrition and Population (HNP) Discussion Paper, World Bank, 2000.

8. de Timóteo Mavimbe, J.C., et al., Immunization coverage in Mozambique: from concepts to decision-making. Health policy, 2006. 79(1): p. 92100.

9. Phuong, C., The international protection of internally displaced persons. Vol. 38. 2005: Cambridge University Press.

10. Huhn, G.D., et al., Vaccination coverage survey versus administrative data in the assessment of mass yellow fever immunization in internally displaced persons-Liberia, 2004. Vaccine, 2006. 24(6): p. 730-737.

11. Connolly, M.A., et al., Communicable diseases in complex emergencies: impact and challenges. The Lancet, 2004. 364(9449): p. 1974-1983.

12. Moss, W.J., et al., Child health in complex emergencies. Bulletin of the World Health Organization, 2006. 84(1): p. 58-64.

13. Nishikiori, N., et al., Who died as a result of the tsunami?-Risk factors of mortality among internally displaced persons in Sri Lanka: a retrospective cohort analysis. BMC public health, 2006. 6(1): p. 73.
14. Feikin, D.R., et al., Mortality and health among internally displaced persons in western Kenya following post-election violence, 2008: novel use of demographic surveillance. Bulletin of the World Health Organization, 2010. 88(8): p. 601-608.

15. Akresh, R., L. Lucchetti, and H. Thirumurthy, Wars and child health: Evidence from the Eritrean-Ethiopian conflict. Journal of development economics, 2012. 99(2): p. 330-340.

16. Brown, D.W. and M. Gacic-Dobo, Home-based record prevalence among children aged 12-23 months from 180 demographic and health surveys. Vaccine, 2015. 33(22): p. 2584-93.

17. Shahab, F., H. Hussain, and H. Gul, Vaccination status and causes of under vaccination in paediatric patients admitted at Khyber teaching hospital Peshawar. Journal of Postgraduate Medical Institute (Peshawar-Pakistan), 2013. 27(4).

18. Melhem, N., K. Kreidieh, and S. Ramia, The Syrian refugees crisis brings challenges to the health authorities in Europe: hepatitis A virus is a case in point. European journal of epidemiology, 2016. 31(7): p. 711-714.

19. Ozaras, R., et al., The Syrian conflict and infectious diseases. Expert review of anti-infective therapy, 2016. 14(6): p. 547-555.

20. Eskiocak, M., B. Marangoz, and N. Etiler, HEALTH PROBLEMS OF REFUGEES. WAR, MIGRATION AND HEALTH; EXPERIENCE OF TURKEY: p. 34.

21. Hemat, S., et al., Health-care provision factors associated with child immunization coverage in a city centre and a rural area in Kabul, Afghanistan. Vaccine, 2009. 27(21): p. 2823-2829.

22. Toole, M.J. and R.J. Waldman, The public health aspects of complex emergencies and refugee situations 1. Annual review of public health, 1997. 18(1): p. 283-312.

23. Siddiqi, N., et al., Assessment of EPI (expanded program of immunization) vaccine coverage in a peri-urban area. JPMA, 2007. 57(8): p. 391-395.

24. Bugvi, A.S., et al., Factors associated with nonutilization of child immunization in Pakistan: evidence from the Demographic and Health Survey 2006-07. BMC Public Health, 2014. 14(1): p. 232.

25. Mohamud, A.N., et al., Immunization coverage of 12-23 months old children and associated factors in Jigjiga District, Somali National Regional State, Ethiopia. BMC Public Health, 2014. 14(1): p. 865.

26. Lakew, Y., A. Bekele, and S. Biadgilign, Factors influencing full immunization coverage among 12-23 months of age children in Ethiopia: evidence from the national demographic and health survey in 2011. BMC public health, 2015. 15(1): p. 728.

27. All, B.D.P.M., E. Child Health. 2012.

28. Akil, L. and H.A. Ahmad, The recent outbreaks and reemergence of poliovirus in war and conflictaffected areas. Int J Infect Dis, 2016. 49: p. 40-6. 
29. Bigna, J.J., Polio eradication efforts in regions of geopolitical strife: the Boko Haram threat to efforts in sub-Saharan Africa. Afr Health Sci, 2016. 16(2): p. 584-7.

30. Fekadu, L., et al., Reaching the unreached with polio vaccine and other child survival interventions through partnership with military in Angola. Vaccine, 2016. 34(43): p. 5155-5158.

31. Norris, A., et al., Crippling Violence: Conflict and Incident Polio in Afghanistan. PLoS One, 2016. 11(3): p. e0149074.

32. Ismail, I.T.A., et al., Assessment of routine immunization coverage in Nyala locality, reasons behind incomplete immunization in south Darfur State, Sudan. Asian journal of medical sciences, 2014. 6(1): p. 1.

33. Kostermans, K., G. Presthus, and C.J. Clements, Situation analysis: new vaccine introduction in an under-performing programme, a dilemma for Pakistan. J Pak Med Assoc, 2013. 63: p. 1458-9.

34. Kaiser, R. and P.B. Spiegel, Humanitarian emergencies, in Nutrition and Health in Developing Countries. 2008, Springer. p. 677-697.

35. Kouadio, I., et al., Outbreak of measles and rubella in refugee transit camps. Epidemiology and infection, 2009. 137(11): p. 1593-1601.

36. Kouadio, I.K., T. Kamigaki, and H. Oshitani, Measles outbreaks in displaced populations: a review of transmission, morbidity and mortality associated factors. BMC Int Health Hum Rights, 2010. 10: p. 5.

37. Lam, E., A. McCarthy, and M. Brennan, Vaccinepreventable diseases in humanitarian emergencies among refugee and internallydisplaced populations. Hum Vaccin Immunother, 2015. 11(11): p. 2627-36.

38. Mahamud, A., et al., Risk factors for measles mortality among hospitalized Somali refugees displaced by famine, Kenya, 2011. Clin Infect Dis, 2013. 57(8): p. e160-6.

39. Teleb, N., et al., Progress toward measles elimination--Eastern Mediterranean Region, 20082012. MMWR Morb Mortal Wkly Rep, 2014. 63(23): p. 511-5. 